\title{
A Minimized Technological Approach towards Human Self Sufficiency off Earth
}

\author{
Peter A. Curreri \\ NASA, Marshall Space Flight Center, Mail Code EM30, Alabama 35812, USA \\ 256 544-7763, peter.a.curreri@nasa.gov
}

\begin{abstract}
Since the early 1970 's it has been known that it is technically feasible to build large habitats in space where many people could live, more or less, independently off Earth. These large habitats would require decades of Apollo level expenditures to build. The objective of this paper is to begin the study of the minimum technological system that will enable the historic shift from the state where all of humanity is dependent on Earth to the state where an independent human community can exist off Earth. It is suggested that such a system is more on the order of a homestead than a city. A minimum technical system is described that could support one human reproductive unit (family) in free space or on a planetary or lunar surface. The system consists of life support, materials extraction, mobility, and power production. Once the technology is developed for the single unit, many could be deployed. They could reproduce themselves at an exponential rate using space resources and energy. One would imagine cooperation of these units to build any combination of towns, cities and nations in space to extend human life beyond Earth.
\end{abstract}

Keywords: Space Resource Utilization, Space Settlement, Space Habitats.

PACS: 87.65.+y, 94.05.Dd.

\section{INTRODUCTION}

These concepts for human settlement of space by using space resources and energy were developed at the time of the first human Moon landings. The Apollo missions were achieved at tremendous cost. One can envision of the massive $300 \mathrm{ft}$. Saturn rocket blasting off from Earth to be almost completely expended with only the tiny capsule splashing down on Earth. Flights to the Moon from Earth are so difficult because, relative to the energy available in chemical propulsion, the Earth is a very large planet. In terms of costs, during Apollo, a pound of material delivered to the Moon from Earth was about $\$ 100,000$ per pound. Conversely, using a lunar resource, after considering the manufacturing costs, can save you the same amount of money. Rocks and soils returned from the Moon verified that lunar soil was a low grade ore containing on average by weight $42 \%$ oxygen, $21 \%$ silicon, $13 \%$ iron, $8 \%$ calcium, $7 \%$ aluminum, $6 \%$. magnesium and $3 \%$ a variety of other trace materials. Relative to Earth the Moon was found deficient in nitrogen, hydrogen, and carbon which are essential to life support. The insight was to use local resources in space to short circuit the expensive barrier of iransportation against Earths substantial gravitational field. It was (and still is) thought that by using in-situ materials and energy that we could develop space on the same scale as we have achieved on Earth.

When the first whole Earth pictures were returned, beginning with Apollo 8, it generated a new conscious appreciation of the fragility of our home planet. On the Moon an astronaut was able to cover the whole Earth view, representing all humanity and all our accomplishments and history, with the thumb of his glove. At the same time nuclear weapon technology developed to the point where most of our culture could be destroyed in a few hours by human action. Thus, the Earth relative to our technological power 
had become a very cramped space. The thin atmosphere shown in the views from space gave rise to sensitivity to pollution. The concept of the Space Solar Power Satellite (Glaser, 1974) was considered, especially when combined with a hydrogen fuel economy, to be a pollution free means to provide unlimited energy to Earth. Twenty $\mathrm{GW}, 12$ by $4 \mathrm{~km}$, stations were envisioned beaming power by microwave beam to Earth. Again the weight of these objects was prohibitive if launched from Earth, but the scheme could be profitable if lunar materials were utilized (Miller and Smith, 1979).

Human history documents continual expansion into new ecosystems by use of technology. With the human Moon landings, many people naturally envisioned living in new worlds beyond Earth: Gerard K. O'Neill devised and popularized an approach to extend human life beyond Earth. Concurrently with the first human Moon landings, Princeton Professor Gerard O'Neill posed this question to his physics students. Where is the best place for an advanced technological society to live? The students realized that just as the surface of the Earth was becoming confining for our advanced technological society, the surfaces of other bodies, the Moon and Mars, would soon present similar limits. The gravity of these bodies would be fixed at below I gravity ( $1 / 6 \mathrm{~g}$ for the Moon and $0.37 \mathrm{~g}$ for Mars). It is unknown whether humans could thrive in continual reduced gravity, since space flights in low g resuited in 1 to 2 percent decalcification of bones per month (National Research Council, 1972). Thus, the surprising answer to this question appeared to be that technically powertiul societies were optimally positioned to live in tree space habitats.

O'Neill's approach (believed to be viable with 1970 's technology) would use space resources (lunar and asteroids) to construct cities in space, each capable of supporting up to 10 million people. By construction of Space Solar Power Satellites, of the type advocated by Peter Glaser in the early 1970s (Glaser, 1974), his analysis predicted in testimony to the Senate Subcommittee on Aerospace Technology (O'Neill, 1975a) that the venture would break-even financially in about 20 years with an Apollo level of investment. The result of this investment could have been abundant cheap energy on Earth and with millions of people living in space by the $1990 \mathrm{~s}$. Of course, as history proved, society was not ready to sustain a leap of this magnitude regardless of the anticipated benefits.

Five years of study of feasibility of space habitats, primarily at Princeton, concluded (ONeill, 1974) that space habitats with beautiful Earth like vistas could be built with 1970 s materials technologies. They could house up to 10 million people each in Earth normal atmosphere and gravity (provided by centrifugal force). Good locations to begin settlement were at the $4^{\text {th }}$ and $5^{\text {th }}$ Earth Moon Lagrange Points (lunar orbit where the Earth's and lunar gravity cancel). Lunar materials, launched from the Moon's $1 / 6 \mathrm{~g}$, required only $1 / 20$ of the energy required from Earth launch, which enabled linear magnetic accelerators to be used to provide materials to the Lagrange points. Further, if the space settlers built Solar Power Satellites as well as habitats, the habitats (O'Neill, 1975b) could pay for themselves after about 20 years of Apollo level investment by providing cheep energy to Earth while enabling millions of people to live in space.

This paper suggests the development of a specific set of technologies which comprise the minimum suite necessary to enable self-sufficient human life beyond Earth. These minimum technologies for human selfsufficiency must include the ability to extract and use the material resources in space, the ability to utilize solar energy, and the ability to build and maintain human habitats each able to support the needs of a human family. These capabilities, in space, would comprise what has historically been called a "homestead."

\section{NASA SPACE SETTLEMENT STUDIES}

NASA Ames and Stanford University hosted comprehensive studies of the space settlement concepts that were chaired by Professor O'Neill in the summers of 1975 (Johnson and Holbrow, 1977) and 1977 (Billingham, Gilbreath and O'Leary, 1979). The habitat geometries considered were expanded to include other shapes than cylinders that could support artificial gravity, the torus, sphere and two smaller spheres rotating on a tether (bolo or dumbbell). The designs targeted a more modest initial population of 10,000 per habitat. 
The use of in-situ derived propellant was studied. It was found that the use of oxygen extracted from lunar soil at a propellant depot at Lagrange Point 2 (where the gravity cancels on a line between the Earth and the Moon) could greatly reduce the transportation costs of the project. However, the major export commodity to Earth from the space settlements remained space solar power. The 1977 report states "No alternative at all was found to the manufacture of solar satellite power plants as the major commercial enterprise of the colony."

The 1975 study focuses on the design of a torus with $1.6 \mathrm{~km}$ major diameter and $130 \mathrm{~m}$ minor diameter. The torus has the advantage (over the large sphere or cylinders) in that the diameter of rotation to attain artificial gravity (major diameter) is independent of the atmospheric volume (minor diameter). The program estimated 22 years to the completion of the first 10,000 person torus. If construction of solar power satellites began after the habitat construction was complete, then 70 years would be required to achieve economic break-even. To alleviate the long uncertainty associated with the long pay back time a plan was developed to begin construction of the space solar power satellites before the first habitat was completed. The plan was to make temporary "construction shacks" in low Earth orbit where about 3000 workers would labor on 6 month shifts constructing the power satellites. This strategy enabled projections of cost break-even at about 30 years from the initiation of the program and only eight years after the first settlement was functioning.

The 1977 study focused more on the large spherical habitat. More attention was paid to the construction methods for the power satellites and lunar materials extraction. Near Earth asteroids as sources of materials was investigated and as well as methods of moving near Earth objects to the settlement vicinity in Lagrange Point 5.

Figure 1 shows the artist renditions of the space settlement concepts studied by NASA. The NASA studies of these designs found no "show stoppers" that would technically prevent these habitats from being build with 1970s technologies. However the expenditures required were way beyond the NASA budget. New launch vehicles, beyond the Space Shuttle would be required including a man rated heavy lift vehicle which would ferry 100 people per trip to the habitats. The substantial new funds required were not allocated to NASA for the development of space settlements and solar power satellites.

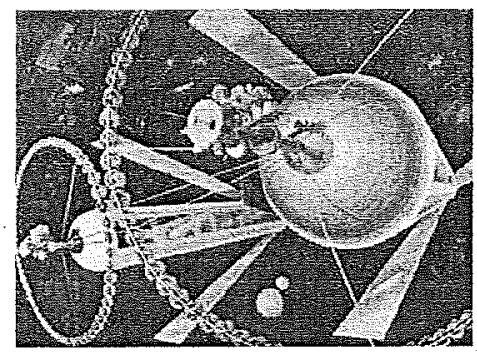

(a)

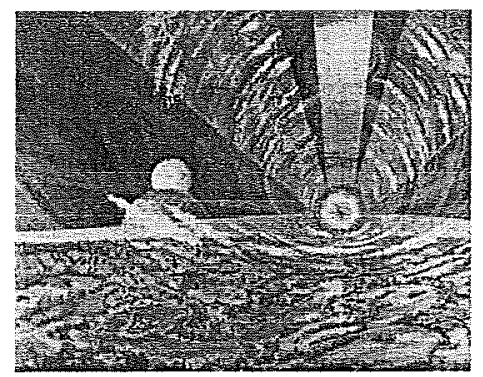

(d)

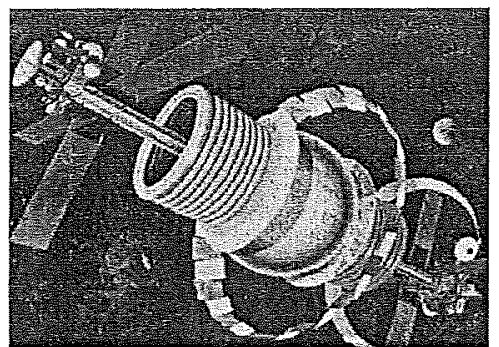

(b)

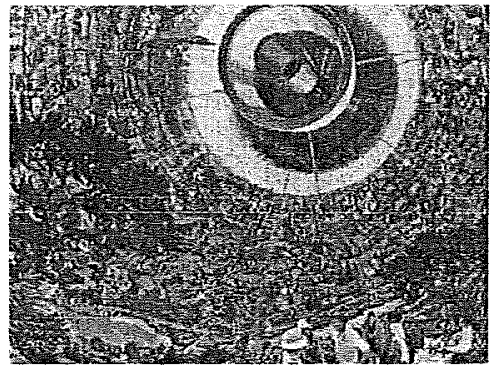

(e)

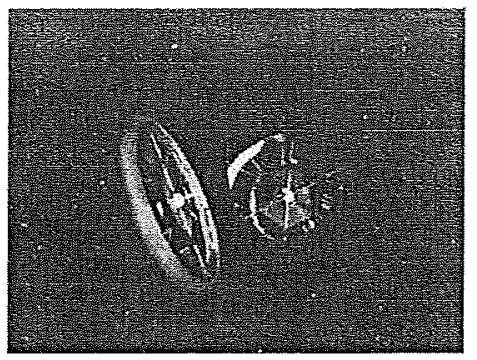

(c)

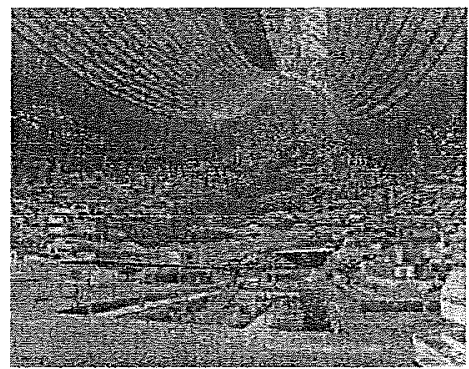

(f)

FIGURE 1 Artists renditions of studied space habitats, outside view and inside view respectively, Cylinders (a), (d); sphere (b), (e); and torus (c), (f) (NASA) 
In 1989 the first President Bush announced an Exploration Initiative and called for a plan for human flight to Mars by 2017. The NASA response included a plan to use lunar resources to produce oxygen for propellant as was suggested in the 1975 settlement study. However, the delta V (energy) necessary to reach Mars is of the same order as that for reaching the Moon and the propellant depot would have to be built in Lagrange Point 2 making this use of space resources for the Mars mission less compelling. In 1997, however, (Hoffman and Kaplan, 1997) a Mars reference mission was designed where the return propellant from Mars would be produced from the Mars carbon dioxide atmosphere. This use of in-situ derived propellant was predicted to enable a human mission to Mars for one tenth the cost. This approach enabled NASA to consider human Mars missions on near flat budget projections.

\section{THE "EXPLORATION VISION"}

NASA is currently pursuing the "Exploration Vision" as articulated by President G.W. Bush, January 14, 2004. The Exploration Vision directs NASA to "extend human presence across the solar system," to "make use of destinations like the Moon and near-Earth asteroids to test and demonstrate new exploration capabilities," "develop and demonstrate power generation," and to "investigate planetary resources." NASA is charged with beginning human expeditions to the Moon in the 2015-2020 time frame. 10 accomplish this NASA is developing a man rated Crew Exploration Vehicle that can travel to the Moon or Mars with a crew of up to six. This is to be launched by a Shuttle derived solid rocket called the Crew Launch Vehicle. It is also developing an unmanned Shuttle derived heavy lift vehicle.

Presently, the United States is set to have humans again leave low Earth orbit and travel towards the Moon for the first time in over 30 years. From past experience we might assume that there will be no large increase in funding for space beyond the current budgets. The question now is can the "Exploration Vision" result in the beginning of self-sustaining self-sufficient human presence in space?

\section{DEFINING A SPACE HOMESTEAD}

The self-sustaining pioneering effort is exemplified in the homestead. The character of the homestead is that it sustains the basic human reproductive unit, which is the family. A human family usually has between 2 and 10 people. Also, the pioneering homesteader would be expected to "live off the land." That is to use the resources at hand to maintain their lifestyle and develop industry. From the industry of a community of homesteaders, exponential economic growth is often possible. The homesteader also has the capability to manufacture more homes for their offspring and new neighbors. This often enables exponential growth in population.

The theme of this paper is to suggest that the place to begin space settlement is with a system more on the order of a homestead than a city. In other words, to study the minimum technological system that will enable the historic shift from the state where all of humanity is dependent on Earth to the state where an independent human community can exist off Earth.

We can begin to sketch a design for the space homestead (Figure 2) using the data (Johnson and Holbrow, 1977; Billingham, Gilbreath and O'Leary, 1979) developed in the past NASA studies. For small volume habitats the geometry that will allow artifieial gravity is the bolo or dumbbell. Each person in the habitat requires about $1,740 \mathrm{~m}^{3}$ of internal volume, so we have two equal spheres of $11 \mathrm{~m}$ internal radius $\left(8,700 \mathrm{~m}^{3}\right.$ each) on opposite sides of a tether to account for 10 people. Of this volume about $91.5 \mathrm{~m}^{3}$ per person is required for producing food, which is $915 \mathrm{~m}^{3}$ of the total habitat volume. The remaining $823 \mathrm{~m}^{3}$ of the habitat volume is for residential requirements. About $5 \mathrm{~m}$ of lunar soil or of water is utilized on the outside of the spheres for shielding from solar radiation and cosmic rays. One gravity is produced at a comfortable spin rate of 1 RPM with a cable length between the spheres of $2 \mathrm{~km}$. A manufacturing pod, capable of reproducing the habitat from available space resources is located at the center of rotation which enables a zero gravity manufacturing environment. Photovoltaic arrays (not shown in Figure 2) provide $3 \mathrm{~kW}$ per person $(30 \mathrm{~kW}$ total) in the habitat. The manufacturing facility is powered by a solar furnace and additional solar arrays. 


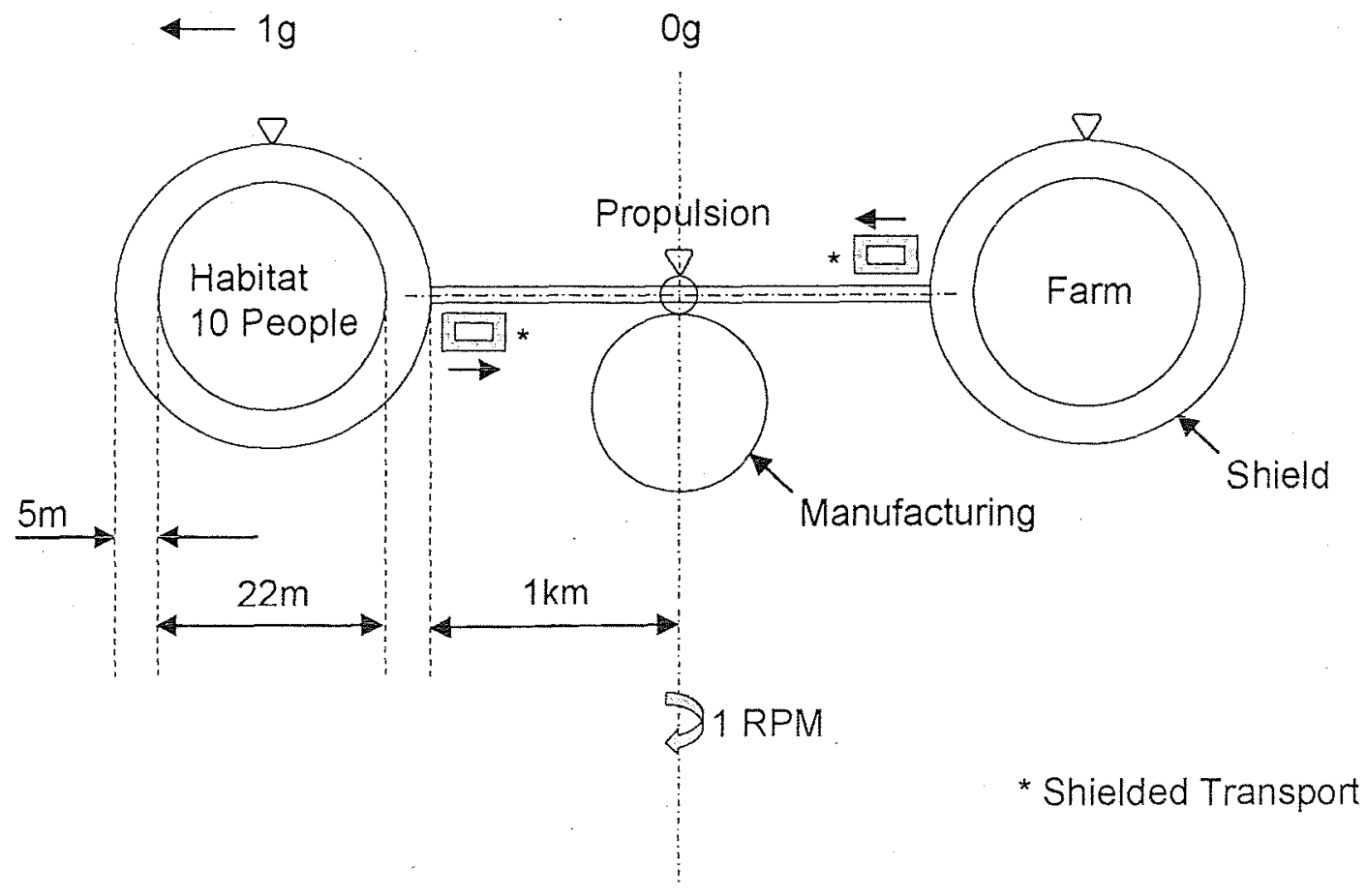

FIGURE 2. Ten Person Humans in the Loop Self-Reproducible Self-Sufficient Habitat in Free Space

\section{EXPANSION TO COMMUNTTES}

Humans establishing homesteads must be able to associate into communities and expend into towns and cities. The bolo configuration for a space settlement was considered in the 1975 NASA study. The study looked at using fifty 200 person spheres to house 10,000 people. The bolo configuration was thought to have the advantage that you could build up the settlement in the same way that cities on Earth develop, one building at a time. It was thought that each small sphere could be manufactured in such a way that it could connect to another enabling the building of composite structures. Figure 3 (Johnson and Holbrow, 1977, NASA) illustrates how multiple bolo habitats can merge to form beaded toruses, cylinders, and spheres. Thus, we might imagine that cooperating bolo habitats could eventually form the long line of sight enclosed environments like those shown in Figure 1.

The NASA studies discarded the bolo habitat idea because in the initial stages the habitats require more shielding mass per person. However, one might imagine the rearrangement of shielding, especially if water is used, when the individual units merge into larger structures. Also as discussed earlier, in order to attain economic break-even for the torus design, it was necessary to employ temporary "construction shacks" in low Earth orbit to house several thousand Solar Power Satellite workers. One might suggest that building smaller permanent habitats in the first decade of construction might the more fruitful approach. The 1975 NASA study estimated that 2,500 man hours would be necessary to build a $10 \mathrm{GW}$ solar power satellite. Thus, if each homestead provided 2.5 man years of labor per year, 200 of them could build a $10 \mathrm{GW}$ space solar power satellite in 5 years.

\section{COMPATIBILITY WITH THE "EXPLORATION VISION"}

Noting the requirements for to support a human family in space, one notes (Figure 4) that by coincidence 

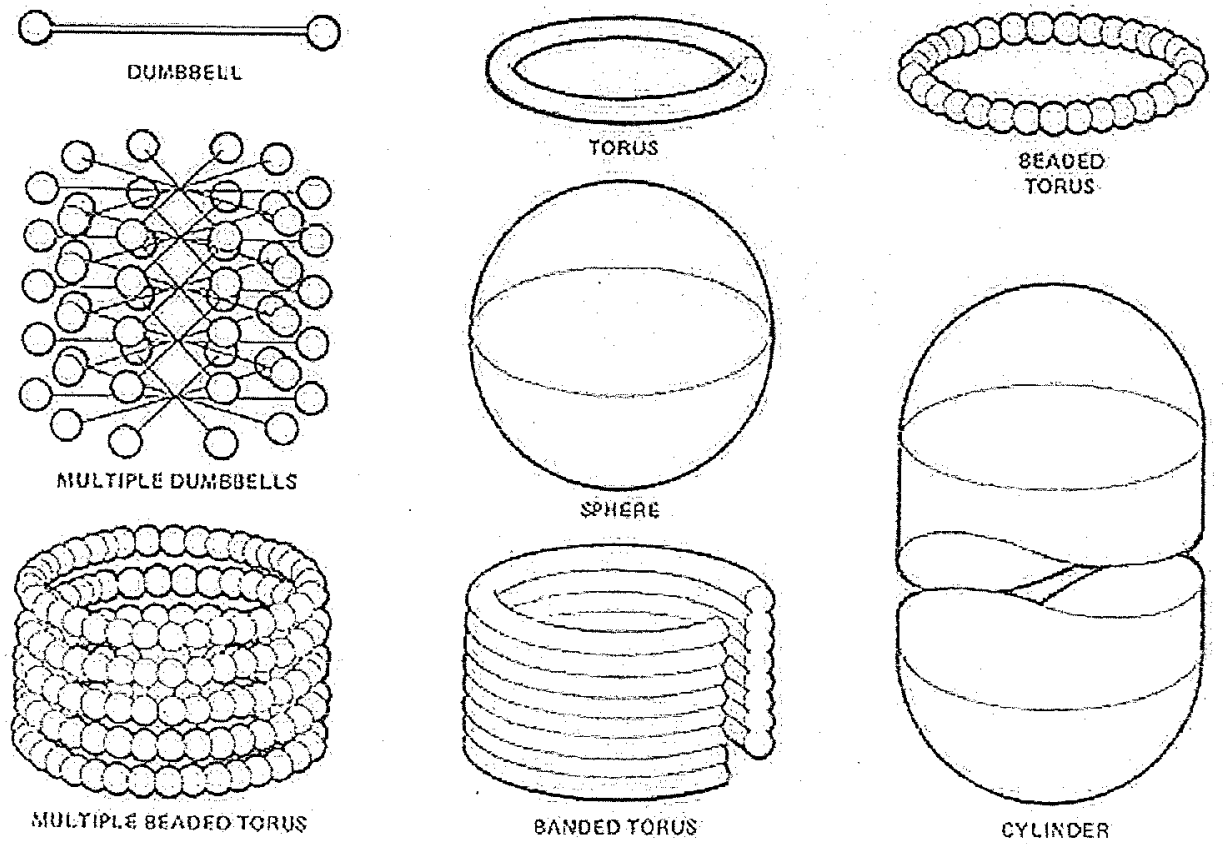

BANOED TORUS

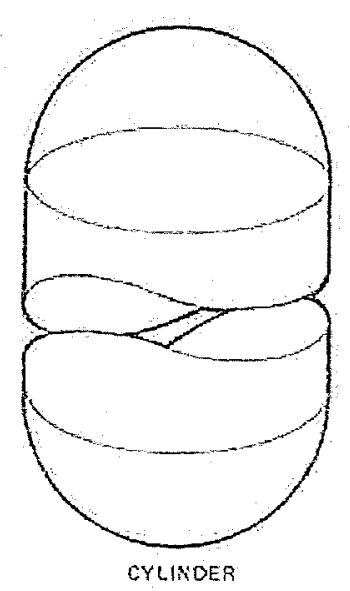

FIGURE 3. Basic and Composite Geometries for Artificial Gravity Space Habitats

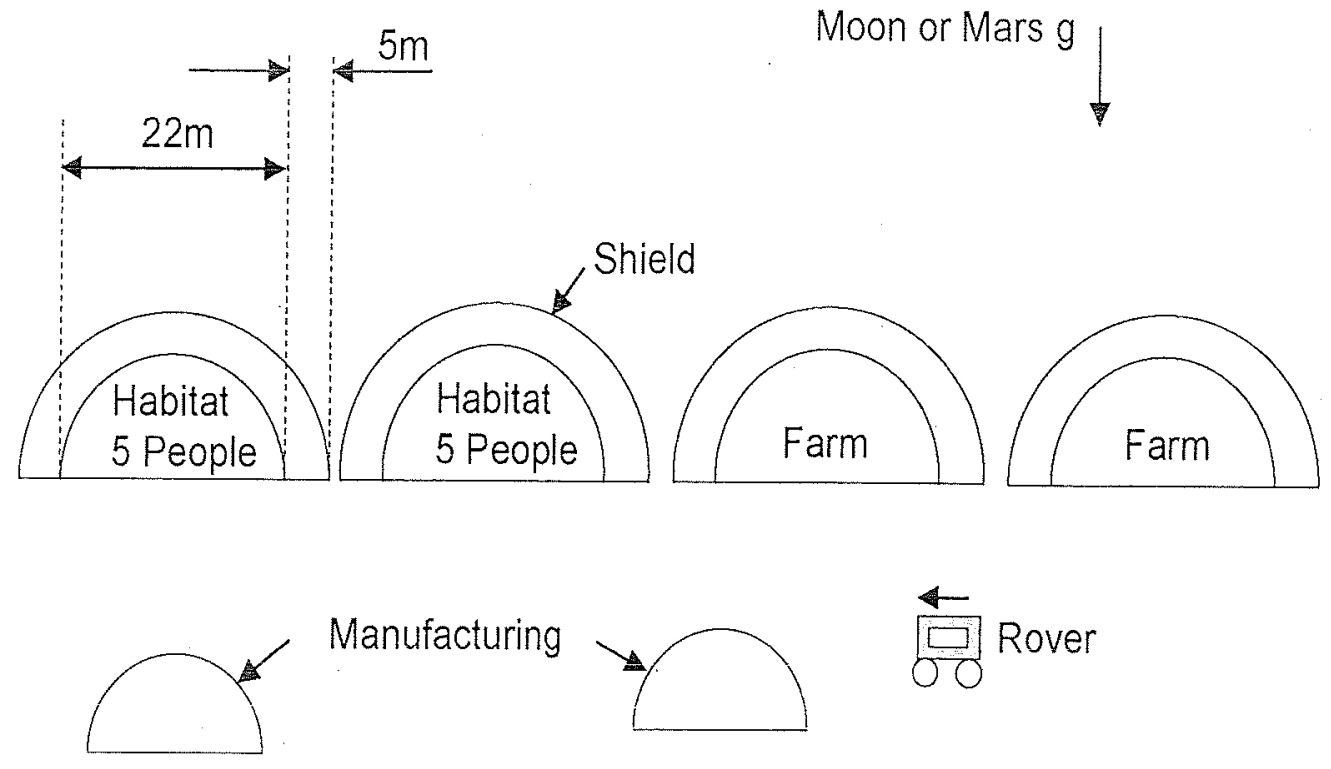

FIGURE 4. Ten person humans in the loop self-reproducible self-sufficient habitat on the moon or Mars 
the space homestead is of the scale that coincides with and can be developed within the scope of the "Exploration Vision." Only a qualitative decision would need to be made by NASA that would redefine the emphasis but not the real content of the program. This compatibility is due to the coincidence that the human family is of the order of 2-10 people. The Crew Exploration Vehicle will be capable of carrying 6 passengers. The lunar base would be expected to have about 6-10 people also. The present plan of a lunar base using space resources is very close to the configuration needed for the simplest human homestead. If emphasis is placed on in situ manufacturing, production of photo voltaic power, and production of food, the "Exploration Vision" could enable the first human self-sufficient off Earth settlement - "extending human presence across the solar system."

\section{ASTEROIDAL COMMUNITIES}

The 1977 NASA study spent considerable effort determining how near Earth asteroids could be moved to the Earth Moon Lagrange point near the settlement. The small mobile habitat concept discussed here would enable the settlers to locate near asteroids resources for production. The low gravity near the asteroid would allow much cheaper resource gathering than even that from the Moons $1 / 6$ gravity. One half of the near Earth asteroids are expected to be extinct comets containing a high percentage of water. Asteroids are also rich in carbon, nitrogen, and hydrogen which are scarce on the Moon. It is estimated (Johnson and Holbrow, 1977; Lewis, 1996) that the main asteroid belt if used for O'Neill habitats could provide the living space of 3000 Earths supporting many trillion people.

\section{CONCLUSIONS}

It is within our technological capability to extend human life beyond Earth by the use of extraterrestrial materials and energy. The space settlement concepts of the 1970 s yield a brilliant vision of new man made worlds in free space, but also require high investments over decades before payback. This paper describes

a minimum approach for human independence in space that is on the scale of the homestead rather than the city. The scale is consistent with the "Exploration Vision" and thus with appropriate program emphasis we might enable a future for humanity that is limited not by this planet but by the universe.

\section{REFERENCES}

Glaser, P.E., et al., "Feasibility Study of a Satellite Solar Power Station," CR-2357, NASA Lewis Research Center, Cleveland, OH, 1974.

Hoffman, S. J. and Kaplan, D. L.., "Human Exploration of Mars: The Reference Mission of the NASA Mars Exploration Study Team," Lyndon B. Johnson Space Center, Houston, TX, (1997), http: //exploration.jsc.nass.gov/marsref/contents.html, accessed September 22, 2006.

Lewis, J.S., Mining the Sky, Helix Books, Reading, MA 1996.

Miller, R.,H. and Smith, B.S., Extraterrestrial Processing and Mamufacturing of Large Space Systems, NASA CR-161293, Lyndon B. Johnson Space Center, Houston, TX, 1979.

The National Research Council, Space Science Board: Human Factors in Long-Duration Spaceflight, National Academy of Sciences, Washington, DC, 1972.

O'Neili, G.K., "The Colonization of Space," Physics Today, 27, 32-34, (1974).

O'Neill, G.K., "Testimony Before the Subcommittee on Space Science and Applications of the Committee on Science and Technology United States House of Representatives, July 23, 1975," 1975a, http://wwy nas.nasa.gov/About/Fducation/SpaceSettlement, accessed September 1, 2006.

O'Neill, G.K, "Space Colonies and Energy Supply to Earth," Science, 10, 943-947 (1975)

Johmson, R. D. and Holbrow, C., eds., Space Settlements, a Design Study, SP.413, NA SA, Washington, D.C. 1977

Billingham, J., Gilbreath, W., and O'Leary, B., eds. Space Resonrces and Space Settlements, SP-428, NASA, Washington, D.C., 1979. 